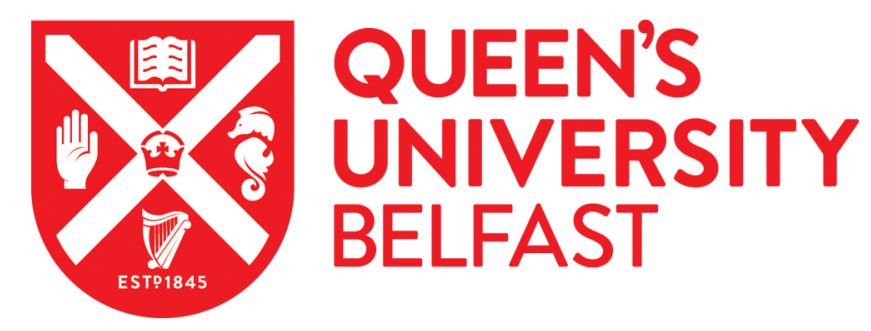

\title{
General practitioners' perceptions of the barriers and solutions to good quality palliative care in dementia
}

Carter, G., Van der Steen, J. T., Galway, K., \& Brazil, K. (2017). General practitioners' perceptions of the barriers and solutions to good quality palliative care in dementia. Dementia:The International Journal of Social Research and Practice, 16(1), 79-95. https://doi.org/10.1177/1471301215581227

Published in:

Dementia:The International Journal of Social Research and Practice

Document Version:

Peer reviewed version

Queen's University Belfast - Research Portal:

Link to publication record in Queen's University Belfast Research Portal

Publisher rights

Copyright 2015 the authors.

\section{General rights}

Copyright for the publications made accessible via the Queen's University Belfast Research Portal is retained by the author(s) and / or other copyright owners and it is a condition of accessing these publications that users recognise and abide by the legal requirements associated with these rights.

Take down policy

The Research Portal is Queen's institutional repository that provides access to Queen's research output. Every effort has been made to ensure that content in the Research Portal does not infringe any person's rights, or applicable UK laws. If you discover content in the Research Portal that you believe breaches copyright or violates any law, please contact openaccess@qub.ac.uk. 
Title page

GPs' perceptions of the barriers and solutions to good quality palliative care in dementia

Gillian Carter ${ }^{1}$, Jenny T van der Steen ${ }^{2}$, Karen Galway ${ }^{1}$ and Kevin Brazil ${ }^{1}$

${ }^{1}$ School of Nursing and Midwifery, Queen's University Belfast, N.Ireland

${ }^{2}$ VU University Medical Center Amsterdam, EMGO Institute for Health and Care Research, Department of General Practice \& Elderly Care Medicine, The Netherlands

\section{Corresponding author}

Gillian Carter, School of Nursing and Midwifery, Queen's University Belfast, Medical Biology Centre, 97 Lisburn Road, Belfast, BT9 7BL, UK.

Email: g.carter@qub.ac.uk 


\section{Abstract}

The general practitioner (GP) is in a pivotal position to initiate and adapt care for their patients living with dementia. This study aimed to elicit GPs' perceptions of the potential barriers and solutions to the provision of good quality palliative care in dementia in their practices.

A postal survey of GPs across Northern Ireland was conducted with open-ended items soliciting for barriers in their practices and possible solutions; $40.6 \%$ (138/340) were returned completed. Barriers to palliative care in dementia were perceived to be a dementia knowledge deficit for healthcare staff and the public; a resource shortfall within the GP practice and community; poor team coordination alongside inappropriate dementia care provision, and disagreements from and within families. These findings have significant implications for educators and clinicians as enhanced dementia education and training were highlighted as a strong agenda for GPs with the suggestions of dementia awareness programs for the public.

\section{Keywords}

Dementia, family carers, general practitioners, palliative care, perceptions 


\section{Background}

Dementia is a significant worldwide health issue, with 35.6 million people living with the condition in 2010 , with the number expected to double by 2030 ,(World Health Organisation, 2012). The General Practitioner (GP) is predominantly the first medical representative to be contacted by patients suffering from dementia, and are generally the only physician involved in making the diagnosis, (Ólafsdóttir, Foldevi, \& Marcusson, 2001; Ólafsdóttir \& Marcusson, 1996). Early identification of symptoms and appropriate individualised interventions are mainly considered to be beneficial, leading to improved outcomes for those living with dementia and their family carers, (Ahmad, Orrell, lliffe, \& Gracie, 2010). However, as dementia is often insidious in onset and difficult to diagnose, GPs have expressed a limited confidence in their diagnostic skills, (Turner et al., 2004; van Hout, Vernooij-Dassen, Poels, Hoefnagels, \& Grol, 2000). This uncertainty extends into their prognostication of the disease (Birch \& Draper, 2008), as a result diagnosing the terminal phase of dementia has been identified as a significant challenge to delivering effective palliative care, (Birch \& Draper, 2008).

Even though many experts of progressive dementias characterise it as a terminal illness, healthcare professionals and family members have difficulty accepting dementia as an illness from which someone can die, often due to its protracted course and the gradual loss of cognition and function, (Sachs, Shega, \& Cox-Hayley, 2004). Nonetheless, recent interest has suggested that a palliative care approach may be beneficial for people with advanced dementia, (Sampson, 2010), but the implementation of this presents unique challenges. As reported by De Vleminck and colleagues, GPs may perceive that the demarcation between regular care and palliative care is not distinct in dementia, (De Vleminck et al., 2014). Furthermore, in the terminal phase the inability of the patient to 
communicate creates additional barriers to effective communication about end-of-life issues and further hinders palliative care, (Birch \& Draper, 2008; Blasi, Hurley, \& Volicer, 2002). Therefore, skillful communication and support from the GP throughout the illness progression is essential to help families negotiate the emotional and psychological challenges surrounding the impact of the condition and end-of-life decision making, (von Gunten, Ferris, \& Emanuel, 2000).

GPs are in a pivotal position to initiate and adapt care for their patients living with dementia, whether they feel correctly trained and supported to do this is questionable. Therefore, identifying the challenges faced by the GPs in this field will help to guide their training and support, and as a result could assist in the provision of sustained and effective palliative care for their dementia patients.

\section{Aim}

This paper reports on GPs' perceptions of the potential barriers and solutions to the provision of good quality palliative care in dementia in their practices.

\section{Methods}

Research Design

A cross-sectional postal survey of GPs located across N.Ireland was conducted in Autumn 2013. A purposive, cluster sampling approach using the Quality and Outcomes Framework (QOF) data (http://www.dhsspsni.gov.uk/index/hss/gp contracts/gp contract qof.htm) with the Business Services Organization's Practice and GP lists (http://www.hscbusiness.hscni.net/services/1816.htm) allowed the creation of a practicelevel sampling frame to target GPs with responsibility for patients with dementia. These 
individuals were registered as having a diagnosis of dementia but it was assumed that they may also have had other co-morbidities. Ethical approval was obtained through the Research Ethics Committee, School of Nursing and Midwifery, Queen's University Belfast.

Participants and procedure. The sample comprised 340 GPs representing 174 practices, each GP receiving a personalised self-complete postal survey. In an effort to maximise response to mail surveys, a system of up to four mail contacts was implemented, (Dillman, Smyth, \& Christian, 2009).

Survey instrument. The 'Care for Dementia Patients at the End of Life' survey instrument explores GPs' perceptions on palliative care for individuals with dementia. The items included in the instrument were based on recommendations proposed by the European Association for Palliative Care (EAPC) on palliative care in dementia, (van der Steen et al., 2014a) and was pretested on a sample of palliative care physicians and GPs. The survey included quantitative evaluation of perceptions of dementia as a terminal illness, communication, Advance Care Planning (ACP), and decision-making. It also evaluated the importance, perceived barriers and challenges of addressing these barriers regarding 12 elements of palliative care in dementia. Following this quantitative evaluation, we solicited respondents' suggestions of the three most significant barriers to the provision of palliative care in dementia in their practices and associated potential solutions, which could be related or unrelated to the quantitative evaluation of elements of palliative care. Finally, respondent characteristics were requested. 
Data management and analysis

Survey data was initially inputted and managed in IBM SPSS Statistics 21 . The free text statements were transferred to QSR NVivo 10 and inductive thematic analysis was completed on the barrier statements only. It was decided that by focusing the thematic analysis on the barrier statements their affiliated solutions would represent prospective solutions for each theme. To ensure validity and rigor, peer checking scrutinised the researcher's interpretation of the data and ensured that these interpretations were a true reflection, (Denzin \& Lincoln, 2005).

\section{Results}

Characteristics of respondents

A total of 138 responses were received, of these 133 provided completed surveys, the remaining five were unable to provide meaningful data, giving a response rate of $40.6 \%$ $(138 / 340)$ representing $60.9 \%$ of the surveyed practices $(106 / 174)$. One to four perceived barriers were provided by $84.2 \%$ of respondents.

\section{Themes}

Five themes (with associated solutions) were identified as overarching barriers to providing good quality palliative care in dementia (Table 1.). The order reflects the frequency of responses by theme. 
Table 1. Themes and subthemes.

\begin{tabular}{|c|c|c|}
\hline Theme & Subthemes & $\begin{array}{l}\text { No. of perceived } \\
\text { barriers provided } \\
\text { by GPs }\end{array}$ \\
\hline $\begin{array}{l}\text { 1.Lack of knowledge } \\
\& \text { understanding }\end{array}$ & $\begin{array}{l}\text { - Level of family/carer understanding } \\
\text { - Recognition that dementia is a palliative } \\
\text { condition by healthcare professionals, families } \\
\text { and the public } \\
\text { - Healthcare Professional understanding, } \\
\text { education \& training } \\
\text { - Level of public understanding }\end{array}$ & 84 \\
\hline $\begin{array}{l}\text { 2.Limited availability } \\
\text { of resources }\end{array}$ & $\begin{array}{l}\text { - GP resources - practice \& time pressures } \\
\text { - Access to community staff \& resources } \\
\text { - Funding }\end{array}$ & 59 \\
\hline $\begin{array}{l}\text { 3.Mismanagement } \\
\text { of appropriate care }\end{array}$ & $\begin{array}{l}\text { - Inappropriate medical treatments, } \\
\text { interventions \& hospitalisations } \\
\text { - Difficulty of assessments, diagnosis \& } \\
\text { prognosis } \\
\text { - Lack of standardised guidelines \& information }\end{array}$ & 62 \\
\hline $\begin{array}{l}\text { 4. Poor } \\
\text { interdisciplinary } \\
\text { team approach }\end{array}$ & $\begin{array}{l}\text { - Team communication, integration \& access to } \\
\text { specialist support } \\
\text { - Continuity of care }\end{array}$ & 52 \\
\hline $\begin{array}{l}\text { 5.Family support \& } \\
\text { involvement }\end{array}$ & $\begin{array}{l}\text { - Family, carer \& patient support } \\
\text { - Family resistance \& disagreements }\end{array}$ & 39 \\
\hline
\end{tabular}

To supplement these survey findings, Tables 2-6 provide illustrative examples of perceived barriers and suggested solutions. 
Table 2. Illustrative examples of perceived barrier statements and suggested solutions to Theme 1.

\begin{tabular}{|c|c|c|}
\hline Theme & Illustrative examples of perceived barriers & $\begin{array}{l}\text { Suggested solutions for } \\
\text { 'Lack of knowledge \& understanding' }\end{array}$ \\
\hline $\begin{array}{l}\text { 1.Lack of } \\
\text { knowledge \& } \\
\text { understanding }\end{array}$ & $\begin{array}{l}\text { Lack of family understanding of condition - unrealistic } \\
\text { goals (R277) } \\
\text { Public understanding of both diagnosis management and } \\
\text { prognosis for patients and family (R121) } \\
\text { The perception in society that dementia patients are a } \\
\text { 'burden' or not worth the same effort as those who have } \\
\text { e.g. 'fought cancer' (R008) } \\
\text { Recognition of the palliative care needs of patients with } \\
\text { dementia (R129) } \\
\text { Lack of acceptance amongst nursing home staff that } \\
\text { palliative care may be appropriate (R144) } \\
\text { Lack of palliative care training of staff in nursing homes } \\
\text { (R166) } \\
\text { Acceptance by clinicians that patients with end stage } \\
\text { dementia require specialist palliative care (R100) }\end{array}$ & $\begin{array}{l}\text { Education provision for families (R076) } \\
\text { Further education is needed for public in terms of what comprises } \\
\text { palliative care [and] what is not appropriate (R335) } \\
\text { Public health education campaign for public to educate them on } \\
\text { signs, strategies for coping with dementia and reducing patient } \\
\text { stress (R017) } \\
\text { Undergraduate and postgraduate education (R129) } \\
\text { Better education for nursing home and primary care teams on } \\
\text { management options for palliative care in dementia (R152) } \\
\text { Organised educational meetings for GPs and associated } \\
\text { professionals (R055) }\end{array}$ \\
\hline
\end{tabular}

\footnotetext{
${ }^{\mathrm{a}}$ Respondent code
} 
Table 3. Illustrative examples of perceived barrier statements and suggested solutions to Theme 2 .

\begin{tabular}{|c|c|c|}
\hline Theme & Illustrative examples of perceived barriers & $\begin{array}{l}\text { Suggested solutions for } \\
\text { 'Limited availability of resources' }\end{array}$ \\
\hline $\begin{array}{l}\text { 2. Limited } \\
\text { availability } \\
\text { of resources }\end{array}$ & $\begin{array}{l}\text { Lack of time - GPs under huge pressure, time involved in } \\
\text { this palliative care is more than GPs can currently } \\
\text { manage (R152) } \\
\text { Having time to spend reviewing patients properly and } \\
\text { speaking to relatives/staff (R251) } \\
\text { Workload - too many patients not enough professionals } \\
\text { (R306) } \\
\text { Increasing number of dementia patients on practice list } \\
\text { and time pressures of home visits (R166) } \\
\text { Lack of support in the community for basic care (R324) } \\
\text { Reduced number of district nurses/ carers in community } \\
\text { to cope with excessive number of palliative care } \\
\text { patients (R204) } \\
\text { Lack of funding for regular care at home (R070) } \\
\text { Lack of investment in placements, support staff, care } \\
\text { packages (R306) }\end{array}$ & $\begin{array}{l}\text { Protected time for palliative care used for dementia patients } \\
\text { (R012) } \\
\text { Better resources to allow time to perform assessments and } \\
\text { reach shared management plans with patients and family } \\
\text { (R209) } \\
\text { Additional funding for nurse specialists in the community } \\
\text { (R076) } \\
\text { Massive increased funding and expansion of GP numbers in } \\
\text { anticipation of increasing elderly population (R006) } \\
\text { Less bureaucracy and more staff (R161) } \\
\text { Invest in staff (R306) }\end{array}$ \\
\hline
\end{tabular}


Table 4. Illustrative examples of perceived barrier statements and suggested solutions to Theme 3.

\begin{tabular}{|c|c|c|}
\hline Theme & Illustrative examples of perceived barriers & $\begin{array}{l}\text { Suggested solutions for } \\
\text { 'Mismanagement of appropriate care' }\end{array}$ \\
\hline $\begin{array}{l}\text { 3.Mismanagement } \\
\text { of } \\
\text { appropriate care }\end{array}$ & $\begin{array}{l}\text { Inappropriate admissions to hospital by nursing home staff } \\
\text { by } 999 \text { ambulance (R299) } \\
\text { Hospital based intervention that is inappropriate (R087) } \\
\text { Nursing home reluctance to allow patients to have no } \\
\text { hospital interventions (R250) } \\
\text { Resuscitation: often not discussed with family/care home } \\
\text { and documented in records (R323) } \\
\text { [Out-of-hours] doctor sending patients to hospital despite } \\
\text { detailed advance care plan, often relatives change mind } \\
\text { (R018) } \\
\text { Reluctance of doctors to stop unnecessary medication } \\
\text { (R022) } \\
\text { Inappropriate treatment with limited benefits (R266) } \\
\text { Some confusing evidence re drug treatment (R302) } \\
\text { Grading of severity of dementia and progress (R291) } \\
\text { Difficulty in predicting prognosis (R037) } \\
\text { Use of guidelines are difficult at times (R107) } \\
\text { Grey area of jurisdiction and law (R294) } \\
\text { Defining the point where 'ordinary' care finishes and } \\
\text { 'palliative' care begins (R158) }\end{array}$ & $\begin{array}{l}\text { All dementia patients should have resuscitation states } \\
\text { discussed and recorded (R323) } \\
\text { Establish protocols of care pathways for patients with } \\
\text { dementia and stop inappropriate aggressive interventions } \\
\text { (R201) } \\
\text { Guidelines suitable for general practice (R302) } \\
\text { Any algorithms whereby prognosis can be more accurate } \\
\text { (R228) } \\
\text { Regular assessment of severity and prognosis ( } \mathbf{R 2 9 1 )} \\
\text { Education and training specific to palliative care in dementia } \\
\text { (R277) } \\
\text { Perhaps a protocol held at practice level, with a 'trigger' } \\
\text { point where we feel we must talk to patient/carers/ family } \\
\text { etc. about the way forward (R228) } \\
\text { Nursing homes to place more importance on advance care } \\
\text { plan - education (R144) }\end{array}$ \\
\hline
\end{tabular}


Table 5. Illustrative examples of perceived barrier statements and suggested solutions to Theme 4.

\begin{tabular}{|c|c|c|}
\hline Theme & Illustrative examples of perceived barriers & $\begin{array}{l}\text { Suggested solutions for } \\
\text { 'Poor interdisciplinary team approach' }\end{array}$ \\
\hline $\begin{array}{l}\text { 4. Poor } \\
\text { interdisciplinary } \\
\text { team approach }\end{array}$ & $\begin{array}{l}\text { Poor communication - hospice or hospital based } \\
\text { consulting/ staff taking action and having discussions } \\
\text { without communicating with the GP (R188) } \\
\text { Patchy specialist support with long waiting lists (R133) } \\
\text { Lack of on-going support from families/carers/fellow } \\
\text { professionals including social workers (R190) } \\
\text { Lack of access to psychogeriatrician (R140) } \\
\text { Limited access to palliative care team as emphasis on } \\
\text { cancer care (R116) }\end{array}$ & $\begin{array}{l}\text { Development of a multidisciplinary team to manage patients with } \\
\text { one person (not necessarily a GP) coordinating care (R055) } \\
\text { More funding for multidisciplinary community dementia teams } \\
\text { (R070) } \\
\text { Some multidisciplinary training; facilitation of joint meetings with } \\
\text { relevant staff (R256) } \\
\text { Better team working/ strengthened links with e.g. Alzheimer's } \\
\text { society etc. (R146) }\end{array}$ \\
\hline
\end{tabular}


Table 6. Illustrative examples of perceived barrier statements and suggested solutions to Theme 5.

\begin{tabular}{|c|c|c|}
\hline Theme & Illustrative examples of perceived barriers & $\begin{array}{l}\text { Suggested solutions for } \\
\text { 'Family support \& involvement' }\end{array}$ \\
\hline $\begin{array}{l}\text { 5. Family support } \\
\& \text { involvement }\end{array}$ & $\begin{array}{l}\text { Lack of support for families in crisis resulting in unnecessary } \\
\text { admissions (R333) } \\
\text { Lack of respite for patients to give carers a rest (R234) } \\
\text { Disputes with families re: expectations of care (R267) } \\
\text { Getting consensus among family members (R263) } \\
\text { Resistance from the patient to be referred for assessment } \\
\text { (R060) } \\
\text { Reluctance of relatives to stop active treatment (R335) } \\
\text { Resistance of family to accept diagnosis and allow patients } \\
\text { to accept residential care (R060) } \\
\text { Resistance to engage in advance care planning by patients } \\
\text { and family (R324) }\end{array}$ & $\begin{array}{l}\text { From diagnosis to palliative state, a dementia team should be } \\
\text { well resourced to assist (R093) } \\
\text { More funding for home support and specialist nurses (R279) } \\
\text { Increased availability of day care facilities for day time respite } \\
\text { would be useful (R065) } \\
\text { Nominate 1-2 family members to represent family views (R263) } \\
\text { It would be useful if information is given at the onset by the } \\
\text { geriatric consultant/ memory clinic for patient and family to } \\
\text { consider. It would be easier to follow on with the discussion if } \\
\text { started in secondary care (R335) }\end{array}$ \\
\hline
\end{tabular}


Lack of knowledge and understanding. The most frequently cited barriers to providing good quality palliative care in dementia were subsumed within this theme and relate to the perceived lack of knowledge and understanding about dementia within the family, healthcare and public domains. The level of family/carer understanding was highlighted by the respondents to be a challenge stemming from the families' lack of awareness of the dementia process. Specifically, hesitance to address the palliative and terminal nature of dementia was an obstacle associated with both the healthcare professionals and family, and was perceived to have a negative impact on subsequent care.

The healthcare professionals were believed to have a limited knowledge of dementia, resulting from a lack of specific education and training opportunities, creating what was felt to be a significant hindrance to dementia care management. The 'Education and training deficiencies' (R235) and the 'lack of skills' (R340) were noted as key inhibitory factors. Extending to the wider public, the respondents believed that the 'public perception' (R294), acceptance and awareness of the condition were important hurdles to be confronted in order to eliminate the misconceptions about dementia.

Enhanced education and training for GPs were suggested solutions to overcome the perceived dearth of dementia knowledge amongst healthcare professionals, with the potential of initial training in undergrad- or postgraduate settings. Media dementia awareness campaigns were felt by the GP respondents to be the best medium to reach all areas of the public.

Limited availability of resources. This theme reflects the logistical, financial and time management barriers to effective dementia care. GP resources incorporating practice and time pressures were of specific concern by the respondents, and believed to significantly 
constrain their ability to provide effective palliative care to their dementia patients, further impinged by a suggested uneven distribution of workload across the healthcare services. Extending beyond the practice, challenges of access to community staff and resources encompassed by a lack of dedicated dementia teams were seen as additional barriers. Finally, funding shortfall was also a perceived key barrier to effective palliative care for dementia patients, with financial limitations believed to diminish the availability of fundamental resources within the GP practice and across primary care.

The proposed solutions were increased funding from health authorities to allow the employment of more healthcare staff and to allow for greater provision of resources. Within the GP practice environment the GPs requested protected time for clinical assessments.

Mismanagement of appropriate care. The GPs highlighted concerns of inappropriate medical treatments with the complexities of assessments and prognostication of dementia, alongside the additional ambiguity caused by legislative considerations and ad hoc implementations of Advance Care Planning (ACP).

The mismanagement of particular interventions and medical treatments were identified by several respondents. Frustration was implied with regards to the appropriateness of the care received by some dementia residents, with unnecessary hospitalisations recognised as a specific barrier to effective care.

The GPs highlighted the challenges associated with clinical assessments, the initial diagnosis and predicting the subsequent progression of dementia. Ultimately, the ability to recognise the end stage of the disease and when to commence palliative care was particularly perplexing. 
Lack of standardised guidelines and information meant that accessing and implementing clearly defined procedures was recognised as a key barrier to palliative care. Ambiguity surrounding end of life choices, uncertainty of legislative procedures and the correct implementation of ACPs created an air of confusion. As such, ACP implementation and management were reported to be inconsistent or inadequately completed.

Overlapping with previous theme solutions, enhanced education and training for GPs and nursing home staff was recommended to resolve this barrier, alongside greater community specialist support, specific practice protocols and accurate prognosis algorithms.

Poor interdisciplinary team approach. A disjointed team was blamed for the breakdown of communication between GP practices and community support, highlighting the 'lack of team approach' (R055) and 'disintegrated primary care teams' (R091) as substantial obstacles. Additionally, a lack of access to or integration with specialist support care professionals/teams was perceived to be a hindrance to providing effective palliative care in dementia. Some respondents felt such support was sporadic, reporting the reluctance of some palliative care teams to become involved.

The consequence of poor team work and ineffective communication was perceived to be the 'inconsistency of care' (R330) received by the dementia patient. Furthermore, the lack of continuous care from one GP along with erratic support outside of normal care hours was recognised to negatively impact dementia management.

Suggestions to rectify poor interdisciplinary team approach included the development of a multidisciplinary team with one person to co-ordinate the dementia care; dedicated and easily accessible community dementia teams, and in general the improvement of team working and links with the community. 
Family support and involvement. The inadequacies of appropriate social support, particularly insufficient respite care, were determined by the respondents to be significant prohibiting factors in the holistic care of someone living with dementia. Furthermore, the difficulties associated with discussing the dying process of a loved one with dementia, and being open about the prognosis were recognised as particular challenges of the GP role. This was felt to be exacerbated by any discord within the family and hindered further by accompanying unrealistic expectations with regards to the individual's symptoms, their life expectancy and medical treatments. As such, resistance or reluctance from family members or the patient were seen as fundamental impediments to the palliative care process, creating obstacles to any ACP discussions.

Optimizing communication and relationships with the families, increasing funding for respite care, nominating family members to represent the individual and named specialist support workers were all recommendations by the GPs to help ease the illness impact on the family and any healthcare repercussions.

\section{Discussion}

The GPs in our study highlighted a large number of barriers to good quality palliative care in dementia, most barriers referring to issues around knowledge and understanding. The discussion of these results will be structured around the five themes in order of priority according to the GPs' frequency of responses. 
Lack of knowledge \& understanding

The GPs identified that within the professional, family and public domains there was a distinct lack of understanding and awareness of dementia. Other research has also demonstrated that physicians need to be more knowledgeable and proactive with respect to their approaches to ACP for patients with Alzheimer's disease, (Cavalieri, Latif, Ciesielski, Ciervo, \& Forman, 2002). The receipt of insufficient basic and post-qualifying training in dementia has also been declared, (Ahmad et al., 2010). Furthermore, education of the healthcare team was highlighted as a core domain by the EAPC in the optimisation of palliative care in dementia, (van der Steen et al., 2014a).

The recommendation of heightened public awareness and of professionals' enhanced dementia education and training is congruent with previous research findings. It has been recognised in Europe that certain barriers to treatment may be founded in a poor awareness of the complexity inherent in the recognition, care and management of dementia, (Bond et al., 2005). It has also been argued that public education is essential to improve community and professional awareness to promote empowerment for the ageing population, (Brown et al., 2005). As such, GPs in Cranney and colleagues' study, (Cranney, Warren, Barton, Gardner, \& Walley, 2001) reacted positively to the suggestion of practicebased learning to assist evidence based guideline implementation, describing a satisfying sense of ownership to the educational process. But, overall, knowledge transfer in dementia not only involves healthcare professionals and academics but also the general public and consumers. 


\section{Limited availability of resources}

The barriers of time pressures, limited funding and insufficient specialist staff are recurring themes in other research with time pressures reported to be the most cited barrier for implementing shared-decision making into clinical practice (Légaré, Ratté, Gravel, \& Graham, 2008). As such the constraints of an eight-minute consultation system have been recognised to limit appropriate assessment of cognitive impairment and care needs with the elderly, (van Hout, Vernooij-Dassen, Bakker, Blom, \& Grol, 2000). Consequently, it is felt that this communication breakdown has led to a crisis-driven approach to dementia care, (Bruce, Paley, Underwood, Roberts, \& Steed, 2002). The GPs in this current study demonstrated particular frustration with time constraints within their surgery, and the challenges of accessing specialist support. Similarly, Turner and collegues reported that GPs' perceived lack of time and lack of social service support were greater obstacles to good dementia care than their own unfamiliarity with current dementia management or with local resources (Turner et al., 2004). Consequently, such obstacles are reported to cause diagnostic delay and prevent appropriate care management of dementia patients and their family carers, (van Hout, Vernooij-Dassen, Poels, et al., 2000).

Protected time and increased funding for extra staff and resources were deemed as logical solutions to the current practice restraints. With increasing demands on their time GPs have had to prioritise their activities (Kaner, Haighton, \& McAvoy, 1998), and in Iliffe and colleagues' research, (lliffe, Wilcock, \& Haworth, 2006) GPs reported that protected time and additional staff were essential for provision of effective dementia care. 


\section{Mismanagement of appropriate care}

Early dementia diagnosis and subsequent prognostications are not straightforward processes for GPs to complete, (Turner et al., 2004; van Hout, Vernooij-Dassen, Bakker, et al., 2000). Early diagnosis permits individuals to receive treatment, care and support, to maximise their independence and to plan for the future, (Department of Health Social Services and Public Safety Northern Ireland, 2011). However, research by Turner and colleagues, (Turner et al., 2004) has demonstrated that one-third of GPs lacked confidence in their diagnostic skills. Furthermore, this diagnostic uncertainty combined with a slow disease manifestation and a fluctuating trajectory, are noted to create significant barriers for GPs, complicating any discussions of diagnosis and care plans, (van Hout, VernooijDassen, Bakker, et al., 2000).

In a focus group study, Flemish GPs reported that Advance Care Planning (ACP) is fundamental for the dementia population, (De Vleminck et al., 2014) as autonomous decision-making (considered a cornerstone of medical ethics) is lost as dementia progresses, (Cavalieri et al., 2002). Nonetheless, due to the difficulties of prognostication and irregular adherence to care plans, the GPs surveyed in the current study perceived both of these as substantial deterrents to dementia care. Previous research has reported that inaccurate prognosis presents one of the most recognized obstacles to good palliative care in the longterm care setting, (Parker-Oliver, Porock, \& Zweig, 2005). As such, two of the domains in the EAPC white paper, (van der Steen et al., 2014a), prognostication and timely recognition of dying, and setting care goals and advance planning have been highlighted as areas that require enhanced guidance in clinical practice, policy and research.

Recommendations of educational support for GPs concentrating on epidemiological knowledge and disclosure of the diagnosis in dementia have been highlighted, (Turner et al., 
2004). In the current study, GPs also recognised this need in combination with greater direction towards implementation and adherence to ACP. As such the necessity of introducing multifaceted, interdisciplinary strategies have been suggested to offset barriers associated with the implementation of ACP across the continuum of care, (Boddy, Chenoweth, McLennan, \& Daly, 2013).

\section{Poor interdisciplinary team approach}

Arguably the core of good clinical practice is good interdisciplinary team work. However, the GPs identified that within their clinical practices poor communication and insufficient integration with other health professionals were an impingement to the palliative care offered to their dementia patients.

Verhey and colleagues recognise that no individual medical speciality has the expertise to manage the multifaceted range of mental, physical and social problems that accompany dementia, (Verhey et al., 1993), consequently an integrated approach to dementia is reported to improve patient outcomes, (Wolfs, Kessels, Dirksen, Severens, \& Verhey, 2008). In particular, Domain 4 of the EAPC white paper, (van der Steen et al., 2014a), highlights the importance of continuous care by all disciplines, however, due to the complexities of caring for a person dying from dementia any improvement of end-of-life care requires a multidisciplinary and holistic team approach, (Sampson, Burns, \& Richards, 2011). As GPs have been recognised as gatekeepers they are well placed to identify early signs of dementia and to enhance access to the range of professionals, (Vernooij-Dassen et al., 2005). However, this would require effective two-way communication and integration with other healthcare professionals, two distinctive barriers to palliative care in dementia identified in the current study. 
Seamless dementia care hinges on the full integration of all parties involved and as contended by Birch and Draper, due to the individualistic nature of end-of-life care this can only be achieved through multidisciplinary teams and suitable guidelines, (Birch \& Draper, 2008). Enhanced multidisciplinary training was requested by the current study GPs, and as highlighted by Vernooij-Dassen and colleagues, determining the diagnosis and subsequent interventions requires collaboration, co-ordination and continuity of care, (Vernooij-Dassen et al., 2005). Conceivably any programme to promote such practice will be pivotal to successful continuous care. A good death with dementia has been defined as one without pain and being surrounded by loved ones, (Lawrence, Samsi, Murray, Harari, \& Banerjee, 2011), and as Sampson and colleagues, (Sampson et al., 2011), state these are not complex goals but ones that require co-operation, communication and integration by and between allied health professionals.

\section{Family support and involvement}

It is well recognised the significant contribution informal carers make to dementia disease management and the subsequent impact of the disease, (Bond et al., 2005; van Hout, Vernooij-Dassen, Bakker, et al., 2000). Crucial to this is having open communication with their healthcare professionals, (Birch \& Draper, 2008; von Gunten et al., 2000). Corresponding with the study GPs' perceptions and suggested solutions, improved communication between carers and GPs is recognised to benefit both the carers and dementia patients, (Bruce et al., 2002). One approach suggested by Bruce and colleagues, from a health promotion angle, was to encourage carers to discuss their problems with the GP, (Bruce et al., 2002). As such family care and involvement is a domain within the EAPC white paper, (van der Steen et al., 2014a), recognising the continual support required by 
family caregivers and their potential of suffering from caregiver burden. Nonetheless, resistance and disagreements by and within families create barriers to consensus building, (Karlawish, Quill, \& Meier, 1999; Robinson \& Kennedy-Schwarz, 2001) and may then produce unnecessary complications in the progression of their family member's care, (van der Steen et al., 2014b). This dilemma is also reported to be a consequence of family reluctance to engage in ACP, (van der Steen et al., 2014b) or due to denial about diagnosis and prognosis from the family and the individual with dementia, (Bruce et al., 2002; van Hout, Vernooij-Dassen, Bakker, et al., 2000). Again, education and awareness are demonstrated to be fundamental factors that could anticipate and alleviate these negative circumstances, (van der Steen et al., 2014a; van Hout, Vernooij-Dassen, Bakker, et al., 2000).

\section{Limitations}

The study sample of GPs was limited to Northern Ireland so caution is advised to applying findings elsewhere. Due to the survey layout of first providing a framework and numerical ratings for barriers to palliative care in dementia, followed by the open-ended questions reported here, this may have guided the respondents' thinking.

Despite vigorous efforts to generate a robust response rate, a low individual GP response is noted. However, most practices included in the survey did participate, offering strong representation at the practice level. Despite the best efforts of total survey design, non-response bias is still possible.

\section{Implications for practice}

The present study and supporting literature demonstrate that enhanced dementia education is a strong agenda for GP training in combination with systematic approaches for 
improved public dementia awareness. Due to the multifaceted impact of the condition, the central role of GPs in dementia care and the significant family participation, substantial multidisciplinary support is crucial to meet the needs of this population.

Future research could use these study findings to determine whether the views expressed are replicated in the GP community across the UK and elsewhere. Consequently, interventions to promote GPs' dementia knowledge and skills are crucial to match the complex requirements of the disease. This has significant implications for educators and clinicians.

\section{Conclusion}

We found that GPs in Northern Ireland perceived five main barriers to providing good quality palliative care in dementia: the lack of dementia knowledge and understanding by healthcare professionals, family and the public; the limited resources and heightened pressures within the GP practice and in the community; the mismanagement of appropriate care provision; the poor interdisciplinary healthcare approach, and finally the resistance and disagreements from families and patients.

Suggested solutions to these barriers were provided by the GPs, with a heavy emphasis on enhanced education and training which appeared to be the inertial point to improving communication and integration across disciplines, and implementation of appropriate care. Additionally, the unequivocal importance of the family involvement and of full public awareness regarding the evolution of dementia were stressed as crucial elements necessary to attain good quality palliative care in dementia. 


\section{Acknowledgements}

The authors would like to thank all the GPs who participated in this survey.

\section{Declaration of conflicting interests}

The authors declare that there are no conflicts of interest.

\section{Funding}

The research was funded by the Care to Know Centre Research Grants Program, Ontario, Canada. 


\section{References}

Ahmad, S., Orrell, M., Iliffe, S., \& Gracie, A. (2010). GPs' attitudes, awareness, and practice regarding early diagnosis of dementia. British Journal of General Practice, 60(578). doi: 10.3399/bjgp10X515386

Birch, D., \& Draper, J. (2008). A critical literature review exploring the challenges of delivering effective palliative care to older people with dementia. Journal of Clinical Nursing, 17(9), 1144-1163. doi: 10.1111/j.1365-2702.2007.02220.x

Blasi, Z. V., Hurley, A. C., \& Volicer, L. (2002). End-of-life care in dementia: A review of problems, prospects and solutions in practice. J Am Med Dir Assoc, 4(2), 101-107.

Boddy, J., Chenoweth, L., McLennan, V., \& Daly, M. (2013). It's just too hard! Australian health care practitioner perspectives on barriers to advance care planning. Australian Journal of Primary Health, 19(1), 38-45. doi: http://dx.doi.org/10.1071/PY11070

Bond, J., Stave, C., Sganga, A., Vincenzino, O., O'Connell, B., \& Stanley, R. L. (2005). Inequalities in dementia care across Europe: key findings of the Facing Dementia Survey. International Journal of Clinical Practice, 59, 8-14. doi: 10.1111/j.1368-504X.2005.00480.x

Brown, M., Grbich, C., Maddocks, I., Parker, D., Connellan, P. R., \& Willis, E. (2005). Documenting end of life decisions in residential aged care facilities in South Australia. Australian and New Zealand Journal of Public Health, 29(1), 85-90.

Bruce, D. G., Paley, G. A., Underwood, P. J., Roberts, D., \& Steed, D. (2002). Communication problems between dementia carers and general practitioners: effect on access to community support services. Med J Aust, 177(4), 186-188.

Cavalieri, T. A., Latif, W., Ciesielski, J., Ciervo, C. A., \& Forman, L. J. (2002). How physicians approach advance care planning in patients with mild to moderate Alzheimer's disease. J Am Osteopathic Assoc, 102(10), 541-544. 
Cranney, M., Warren, E., Barton, S., Gardner, K., \& Walley, T. (2001). Why do GPs not implement evidence-based guidelines? A descriptive study. Family Practice, 18(4), 359-363. doi: 10.1093/fampra/18.4.359

De Vleminck, A., Pardon, K., Beernaert, K., Deschepper, R., Houttekier, D., Van Audenhove, C., ... Vander Stichele, R. (2014). Barriers to Advance Care Planning in Cancer, Heart Failure and Dementia Patients: A Focus Group Study on General Practitioners' Views and Experiences. Plos One, 9(1). doi: 10.1371/journal.pone.0084905

Denzin, N. K., \& Lincoln, Y. S. (Eds.). (2005). The Sage Handbook of Qualitative Research (3rd ed.) (3rd ed.). Thousand Oaks, CA: Sage.

Department of Health Social Services and Public Safety Northern Ireland. (2011). Improving Dementia Services in Northern Ireland: A Regional Strategy. Retrieved from http://www.dhsspsni.gov.uk/improving-dementia-services-in-northern-ireland-a-regionalstrategy-november-2011.pdf.

Dillman, D., Smyth, J., \& Christian, L. H. (2009). Internet, Mail and Mixed-Mode Surveys: The Tailored Design Method (3rd ed.). Hoboken, New Jersey: John Wiley \& Sons.

Iliffe, S., Wilcock, J., \& Haworth, D. (2006). Obstacles to Shared Care for Patients with Dementia: A qualitative study. Family Practice, 23(3), 353-362. doi: 10.1093/fampra/cmi116

Kaner, E. F., Haighton, C. A., \& McAvoy, B. R. (1998). 'So much post, so busy with practice--so, no time!': a telephone survey of general practitioners' reasons for not participating in postal questionnaire surveys. British Journal of General Practice, 48(428), 1067-1069.

Karlawish, J. H. T., Quill, T., \& Meier, D. E. (1999). A Consensus-Based Approach To Providing Palliative Care to Patients Who Lack Decision-Making Capacity. Annals of Internal Medicine, 130(10), 835-840. doi: 10.7326/0003-4819-130-10-199905180-00018

Lawrence, V., Samsi, K., Murray, J., Harari, D., \& Banerjee, S. (2011). Dying well with dementia: qualitative examination of end-of-life care. The British Journal of Psychiatry, 199(5), 417-422. doi: 10.1192/bjp.bp.111.093989 
Légaré, F., Ratté, S., Gravel, K., \& Graham, I. D. (2008). Barriers and facilitators to implementing shared decision-making in clinical practice: Update of a systematic review of health professionals' perceptions. Patient Education and Counseling, 73(3), 526-535. doi: http://dx.doi.org/10.1016/j.pec.2008.07.018

Ólafsdóttir, M., Foldevi, M., \& Marcusson, J. (2001). Dementia in primary care: why the low detection rate? Scand J Prim Health Care, 19(3), 194-198.

Ólafsdóttir, M., \& Marcusson, J. (1996). Diagnosis of dementia at the primary care level. Acta Neurologica Scandinavica, 94(S165), 58-62. doi: 10.1111/j.1600-0404.1996.tb05873.x

Parker-Oliver, D., Porock, D., \& Zweig, S. (2005). End-of-Life Care in U.S. Nursing Homes: A Review of the Evidence. Journal of the American Medical Directors Association, 6(3, Supplement), S21S30. doi: http://dx.doi.org/10.1016/j.jamda.2005.03.017

Robinson, E. M., \& Kennedy-Schwarz, J. (2001). Caring for incompetent patients and their surrogates. The American Journal of Nursing, 101(7), 75-76.

Sachs, G. A., Shega, J. W., \& Cox-Hayley, D. (2004). Barriers to excellent end-of-life care for patients with dementia. Journal of General Internal Medicine., 19(10), 1057-1063. doi: $10.1111 / \mathrm{j} .1525-1497.2004 .30329 . x$

Sampson, E. L. (2010). Palliative care for people with dementia. British Medical Bulletin, 96(1), 159174. doi: $10.1093 / \mathrm{bmb} / \mathrm{ldq} 024$

Sampson, E. L., Burns, A., \& Richards, M. (2011). Improving end-of-life care for people with dementia. The British Journal of Psychiatry, 199(5), 357-359. doi: 10.1192/bjp.bp.111.097030

Turner, S., Iliffe, S., Downs, M., Wilcock, J., Bryans, M., Levin, E., .. O'Carroll, R. (2004). General practitioners' knowledge, confidence and attitudes in the diagnosis and management of dementia. Age Ageing, 33(5), 461-467. doi: 10.1093/ageing/afh140

van der Steen, J. T., Radbruch, L., Hertogh, C. M., de Boer, M. E., Hughes, J. C., Larkin, P., . . Volicer, L. (2014a). White paper defining optimal palliative care in older people with dementia: A 
Delphi study and recommendations from the European Association for Palliative Care.

Palliative Medicine, 28(3), 197-209. doi: 10.1177/0269216313493685

van der Steen, J. T., van Soest-Poortvliet, M. C., Hallie-Heierman, M., Onwuteaka-Philipsen, B. D., Deliens, L., de Boer, M. E., . . . de Vet, H. C. (2014b). Factors associated with initiation of advance care planning in dementia: a systematic review. J Alzheimers Dis, 40(3), 743-757. doi: $10.3233 /$ jad-131967

van Hout, H., Vernooij-Dassen, M., Bakker, K., Blom, M., \& Grol, R. (2000). General practitioners on dementia: tasks, practices and obstacles. Patient Education and Counseling, 39(2-3), 219225. doi: http://dx.doi.org/10.1016/S0738-3991(99)00034-8

van Hout, H., Vernooij-Dassen, M., Poels, P., Hoefnagels, W., \& Grol, R. (2000). Are general practitioners able to accurately diagnose dementia and identify Alzheimer's disease? A comparison with an outpatient memory clinic. British Journal of General Practice, 50(453), 311-312.

Verhey, F. R., Jolles, J., Ponds, R. W., Rozendaal, N., Plugge, L. A., de Vet, R. C., . . van der Lugt, P. J. (1993). Diagnosing dementia: a comparison between a monodisciplinary and a multidisciplinary approach. J Neuropsychiatry Clin Neurosci, 5(1), 78-85.

Vernooij-Dassen, M. J. F. J., Moniz-Cook, E. D., Woods, R. T., Lepeleire, J. D., Leuschner, A., Zanetti, O., ... Iliffe, S. (2005). Factors affecting timely recognition and diagnosis of dementia across Europe: from awareness to stigma. Int J Geriatr Psychiatry, 20(4), 377-386. doi: 10.1002/gps.1302

von Gunten, C. F., Ferris, F. D., \& Emanuel, L. L. (2000). Ensuring competency in end-of-life care: Communication and relational skills. JAMA, 284(23), 3051-3057. doi: 10.1001/jama.284.23.3051

Wolfs, C. A. G., Kessels, A., Dirksen, C. D., Severens, J. L., \& Verhey, F. R. J. (2008). Integrated multidisciplinary diagnostic approach for dementia care: randomised controlled trial. The British Journal of Psychiatry, 192(4), 300-305. doi: 10.1192/bjp.bp.107.035204 
World Health Organisation. (2012). Dementia a Public Health Priority. Geneva: World Health Organisation Retrieved from

http://whqlibdoc.who.int/publications/2012/9789241564458 eng.pdf. 